\title{
Trends in prediabetes and diabetes prevalence and associated risk factors in Vietnamese adults
}

\author{
That Thanh Ton ${ }^{1 *}$, Anh Thi Ngoc Tran ${ }^{2 *}$, Ich Thanh Do ${ }^{1 *}$, Hoa Nguyen' , Thi Thanh Binh Nguyen ${ }^{3}$, \\ Minh Tu Nguyen ${ }^{3}$, Van Anh Bao Ha ${ }^{4}$, Anh Quoc Tran ${ }^{4}$, Huu Khoi Hoang ${ }^{4}$, Binh Thang Tran ${ }^{2}$ \\ 'Da Nang Center for Disease Control and Prevention, Da Nang, Vietnam; '2Department of Cancer Control and Population Health, Graduate \\ School of Cancer Science and Policy, National Cancer Center, Goyang, Korea; ${ }^{3}$ Hue University of Medicine and Pharmacy, Hue University, Hue, \\ Vietnam; ${ }^{4}$ Da Nang University of Medical Technology and Pharmacy, Da Nang, Vietnam
}

\begin{abstract}
OBJECTIVES: The prevalence of diabetes mellitus is rapidly increasing in Vietnam, particularly among adults aged over 45 years. This study estimated trends in diabetes and prediabetes prevalence and determined risk factors in Vietnamese adults (over 45 years).

METHODS: A cross-sectional study was conducted based on data from an annual diabetes screening program among people aged 45-69 years in an urban city in central Vietnam (Da Nang). Joinpoint regression analyses were performed to calculate the annual percentage change and $\mathrm{p}_{\text {trend }}$-values. Multinomial logistic regression analysis was used to determine risk factors.

RESULTS: In total, 3,765 men and 9,149 women were included in this analysis. The age-adjusted prevalence of diabetes and prediabetes in 2017 was $11.4 \%$ and $52.9 \%$, respectively. The prevalence of diabetes was higher in men (15.1\%) than in women (10.3\%), but that of prediabetes was similar in both genders (53.4\% vs. $52.8 \%)$. The prevalence of prediabetes significantly increased during the study period, whereas no upward or downward trend for diabetes was observed. The prevalence of obesity, abdominal obesity, hypertension, and dyslipidemia showed no obvious trend. Obesity, a high waist-to-hip ratio, hypertension, more severe abdominal obesity, and dyslipidemia were significantly associated with a higher risk of diabetes and prediabetes. CONCLUSIONS: Diabetes and prediabetes were more prevalent among people aged over 45 years than in the general population. Da Nang has experienced a marked increase in the prevalence of prediabetes. These findings have significant implications regarding the need for nationwide public health interventions and management aiming at diabetes prevention and control.
\end{abstract}

KEY WORDS: Diabetes mellitus, Prediabetic state, Trend analysis, Risk factors, Vietnam

\section{INTRODUCTION}

Diabetes mellitus is a chronic metabolic disease characterized by elevated blood sugar levels. It is 1 of 4 serious non-communi-

\section{Correspondence: Binh Thang Tran}

Department of Cancer Control and Population Health, Graduate

School of Cancer Science and Policy, National Cancer Center,

323 Ilsan-ro, Ilsandong-gu, Goyang 10408, Korea

E-mail: binhthang1001@gmail.com

*Ton, Tran, and Do contributed equally to this work as joint first authors. Received: Apr 3, 2020 / Accepted: May 10, 2020 / Published: May 11, 2020

This article is available from: https://e-epih.org/

(c) This is an open-access article distributed under the terms of the Creative Commons Attribution License (https://creativecommons.org/licenses/by/4.0/), which permits unrestricted use, distribution, and reproduction in any medium, provided the original work is properly cited.

(C) 2020, Korean Society of Epidemiology cable diseases (NCDs) that the World Health Organization (WHO) has targeted for control [1]. Diabetes develops when an individual's pancreas does not make enough insulin, or the body cannot effectively use the insulin it produces. Diabetes results in abnormal carbohydrate metabolism and elevated blood glucose levels, which subsequently lead to severe health complications including vision loss, leg amputation, heart attack, stroke, kidney failure, and nerve damage; furthermore, diabetes even increases the risk of developing some types of cancer [1,2]. Undiagnosed cases of diabetes or prediabetes are an emerging public health concern, as many instances are only identified after affected individuals develop serious complications [3]. Approximately 5-10\% of individuals with prediabetes will develop diabetes within the next 10 years if their condition is not controlled appropriately, and they may experience diabetic complications [4]. As a result, prediabetes is a significant risk factor of diabetes, and this recognition should be combined with a thorough understanding of its natural 
history and interventions to control it.

Diabetes imposes a significant burden of disease in Vietnam [5]. The nationwide prevalence of diabetes was $6.0 \%$ in 2017, with approximately 5 million adults diagnosed with diabetes [1]. In the same year, diabetes accounted for 29 out of 1,000 deaths, of which $51.5 \%$ were among undiagnosed cases [6]. The economic burden of diabetes currently accounts for $12 \%$ of the gross domestic product per capita [7]. The burden of diabetes is increasing, and it deserves more attention since it constitutes one of the largest challenges facing Vietnam due to the aging population. Evidence from previous studies in Vietnam reveals that the prevalence of diabetes was higher among those aged over 40 years [8-10]. Demographic changes, coupled with income growth and a westernized lifestyle, particularly in the city of Da Nang (a coastal city that is the largest city in central Vietnam, with 1.134 million inhabitants), will change the distribution of diabetes in the future [11]. Therefore, controlling diabetes and prediabetes in high-risk people aged over 45 years old is likely to play a crucial role in the management of NCDs. However, analyses of trends in prediabetes and diabetes using primary data to suggest appropriate public health policy have not yet been conducted in Vietnam.

In the present study, we aimed to estimate the trends in prediabetes and diabetes prevalence and to determine related risk factors among Vietnamese people aged 45 years and older in Da Nang, Vietnam, from 2011 to 2017.

\section{MATERIALS AND METHODS}

\section{Study population}

This study employed a cross-sectional design using data extracted from the Provincial Non-Communicable Disease Screening program, specific to diabetes, over the period of 2011-2017. An annual screening program was undertaken in Da Nang, consisting of 1 sub-urban district (defined as a rural area in the study) and 6 urban districts.

In brief, the diabetes prevention program was a part of an NCDs screening program that has been implemented in some targeted provinces and cites since 2010. This program is managed by the Ministry of Health and technically supervised by the Vietnam National Hospital of Endocrinology. The funding partially comes from the budget of the national project and mostly relies on funding availability from the Provincial People's Department. This program was carried out by the Da Nang Center for Disease Control and Prevention.

The program used a multistage sampling method: (1) 3 districts of the city of Da Nang were selected randomly based on the characteristics of different ecological regions; (2) 4-6 communes in each district were then randomly selected; (3) 10 villages were randomly selected from each commune; and (4) a list of people aged 45 and older of both genders in the studied villages was compiled from the list of total residents. From 2011 to 2017, a total of 21,318 people were randomly selected and invited, of whom 13,389 people agreed to take part in the program.
The screening program consisted of a survey about health behaviors and a health examination. We excluded non-residents of Da Nang and who did not either answer a health behavior survey questionnaire, had missing blood sample, or duplicated subjects. In total, 12,725 respondents were eligible for our present study.

\section{Measurements and definitions}

Information was collected on the demographic characteristics of study participants, including age, gender, educational level, and residential area.

Diabetes and prediabetes measurements and classification followed the standards of the American Diabetes Association. Diabetes was defined as a fasting plasma glucose (FPG) $\geq 6.993 \mathrm{mmol} / \mathrm{L}$ or a 2-hour postload oral glucose tolerance test (OGTT) level $\geq 11.045 \mathrm{mmol} / \mathrm{L}$. Prediabetes was classified as FPG of 5.550$6.993 \mathrm{mmol} / \mathrm{L}$ or a 2-hour postload OGTT level of 7.77-11.045 $\mathrm{mmol} / \mathrm{L}[12]$. All blood glucose tests were carried out by health professionals at commune health centers. The Johnson and Johnson SureStep OneTouch glucose meter (Johnson \& Johnson, New Brunswick, NJ, USA) was used to test either the FPG level or OGTT level at the same laboratory (Da Nang Center for Disease Control and Prevention).

Hypertension was defined as a systolic blood pressure (SBP) higher than $140 \mathrm{mmHg}$ or a diastolic blood pressure (DBP) exceeding $90 \mathrm{mmHg}$ [13].

Body mass index (BMI) was calculated by dividing weight by height squared $\left(\mathrm{kg} / \mathrm{m}^{2}\right)$. Obesity was identified as a BMI $\geq 25 \mathrm{~kg} / \mathrm{m}^{2}$, following the WHO criteria of BMI cut-off points for Asia-Pacific people [14].

Waist circumference was measured using a constant-tension tape at the umbilicus level. Hip circumference was measured at the level of the broadest border over the great trochanters. Abdominal obesity was defined as a waist circumference $\geq 80 \mathrm{~cm}$ for women and $\geq 94 \mathrm{~cm}$ for men $[14,15]$.

Waist-to-hip ratio (WHR) was defined as the waist circumference in meters divided by the hip circumference in meters. A high WHR was classified as $\geq 0.9$ for men and $\geq 0.8$ for women.

Dyslipidemia was measured by the self-reported question: "Have you ever had dyslipidemia before?" and classified based on study participants' answers (yes or no).

\section{Statistical analysis}

The study participants' demographic characteristics and related health status in each year were summarized using number and frequency. We calculated the crude prevalence of prediabetes and diabetes, and then employed the direct age standardization method to estimate the age-adjusted prediabetes/diabetes prevalence using the referenced age groups in the 2009 Vietnamese Census (above 45 years old), stratified by demographic characteristics. We conducted a similar analysis for prediabetes/diabetes prevalence based on FPG levels alone, details on which are provided in the Supplementary Materials 1 and 2.

Multinomial logistic regression models were performed to de- 


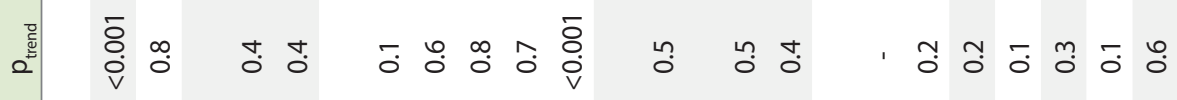

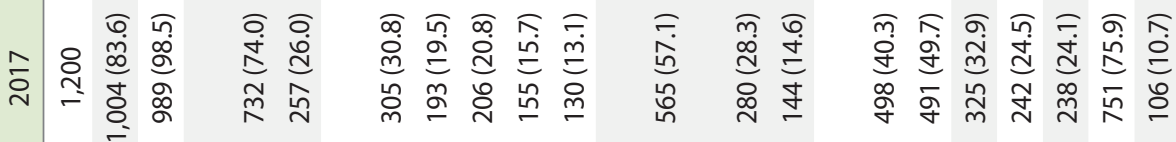

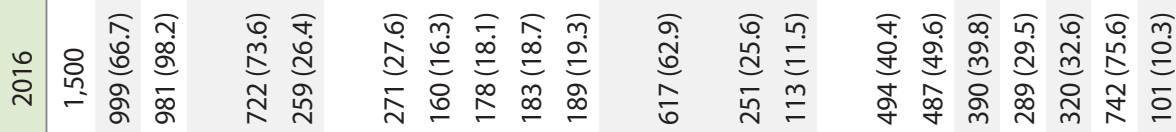

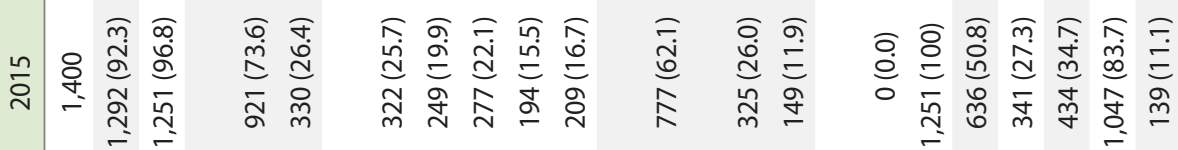

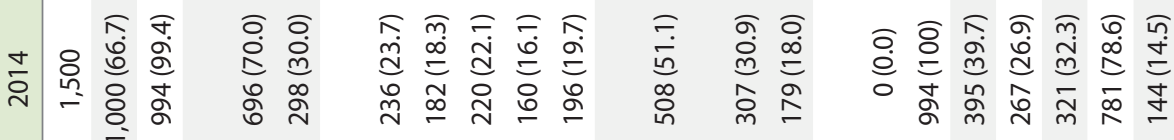

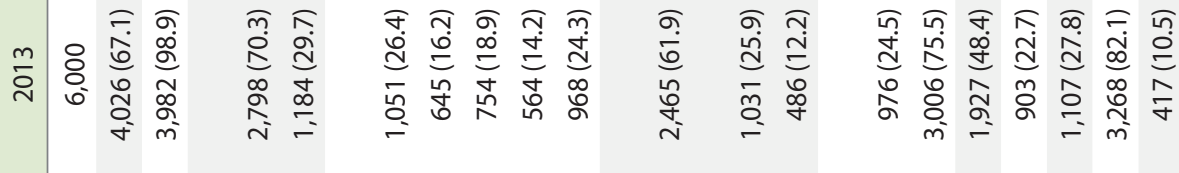

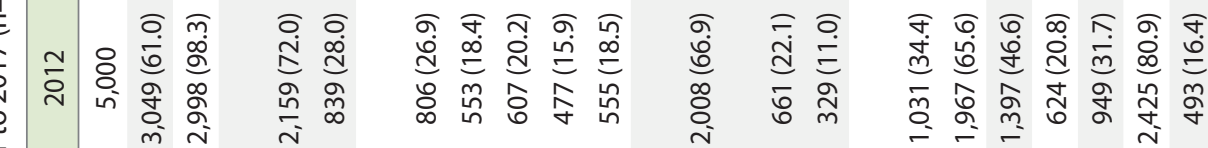

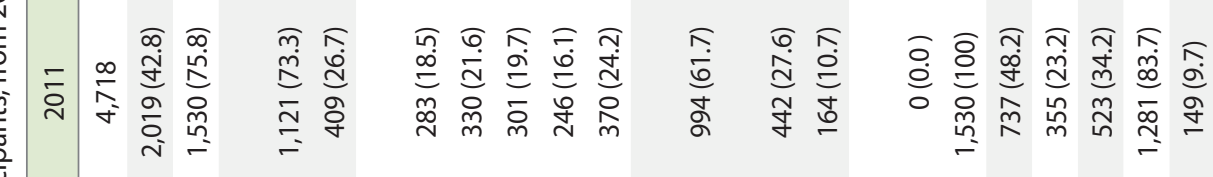

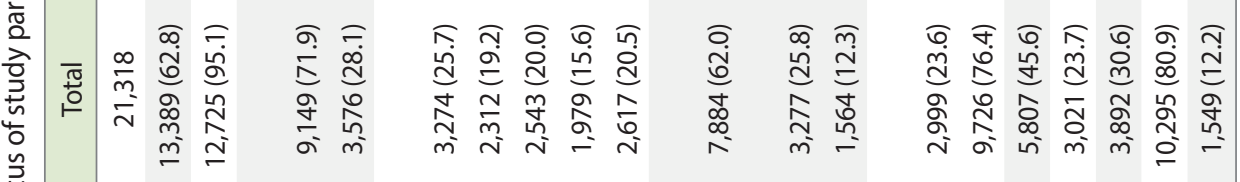


termine the risk factors of diabetes and prediabetes. The overall and gender-stratified models were employed separately. Binary logistic regression was also utilized for the composite outcome of interest (prediabetes and diabetes), and the results are provided in the Supplementary Material 3.

The Joinpoint software (developed by IMS, Inc. under contract for the National Cancer Institute of America) was applied to estimate the annual percentage change (APC) and $\mathrm{p}_{\text {trend }}$-values.

The threshold for statistical significance was set as a p-value of less than 0.05. Stata version 14 (StataCorp., College Station, TX, USA) was used for all data management and analysis.

\section{Ethics statement}

The scientific committee at the Center for Disease Control and Prevention (formerly named: Da Nang City Preventive Medicine Center) and the Department of Health in Da Nang agreed for us to use data since 2016 (Decision No.1659/QĐ-SYT). In addition, ethical approval for the study protocol was obtained from the Ethics Committee for Biomedical Researches of Hue University of Medicine and Pharmacy, Hue, Vietnam (No. H2016/78, date of approval: May 12, 2016).

All participants were given information about screening and provided written informed consent for the annual screening program.

\section{RESULTS}

Descriptive statistics on participation rates, socio-demographic characteristics of the study participants, and related health status during the study period are shown in Table 1 . In total, 12,725 people were included in this study. The overall participation rate was $62.8 \%$, with a significant increase from $42.8 \%$ in 2011 to $83.6 \%$ in 2017 ( $\left.\mathrm{p}_{\text {trend }}<0.05\right)$. The highest participation rate was observed in 2015 (92.3\%). Two-thirds of the sample were women (71.9\%). There was a trend towards increased participation by people in the age group of $65-69\left(\mathrm{p}_{\text {trend }}<0.05\right)$. Over $50 \%$ of the study participants had an education level of lower than high school. Most of the respondents reported living in urban areas (76.4\%). The prevalence of obesity, abdominal obesity, hypertension, and dyslipidemia was stably constant ( $\mathrm{p}_{\text {trend }}>0.05$ ).

Table 2 shows the trends in the crude and age-standardized prevalence of diabetes. The crude and adjusted prevalence of diabetes showed no significant changes $\left(\mathrm{p}_{\text {trend }}=0.3\right.$ and $\mathrm{p}_{\text {trend }}=0.2$, respectively). The age-standardized prevalence for diabetes was $11.8 \%$ in 2011 and $11.4 \%$ in 2017. No significant changes in diabetes were noted according to age group, gender, residential area, or educational level ( $\left.\mathrm{p}_{\text {trend }}>0.05\right)$.

As shown in Table 3, the unadjusted and adjusted prevalence of prediabetes significantly increased. The age-standardized preva-

Table 2. Age-standardized prevalence of diabetes among study participants $(n=12,725)^{1}$

\begin{tabular}{|c|c|c|c|c|c|c|c|c|c|}
\hline Characteristics & 2011 & 2012 & 2013 & 2014 & 2015 & 2016 & 2017 & APC (\%) & $p_{\text {trend }}$ \\
\hline No. of respondents (n) & 1,530 & 2,998 & 3,982 & 994 & 1,251 & 981 & 989 & - & - \\
\hline No. of participants with diabetes (n) & 217 & 281 & 424 & 136 & 190 & 157 & 117 & - & - \\
\hline \multicolumn{10}{|l|}{ Prevalence } \\
\hline Crude & $14.2 \pm 0.9$ & $9.4 \pm 0.5$ & $10.6 \pm 0.5$ & $13.7 \pm 1.1$ & $15.2 \pm 1.0$ & $16.0 \pm 1.2$ & $11.8 \pm 1.0$ & 4.55 & 0.3 \\
\hline Adjusted & $11.8 \pm 0.9$ & $8.6 \pm 0.5$ & $8.8 \pm 0.5$ & $12.1 \pm 1.1$ & $13.5 \pm 1.0$ & $14.2 \pm 1.1$ & $11.4 \pm 1.0$ & 6.23 & 0.2 \\
\hline \multicolumn{10}{|l|}{ Age (yr) } \\
\hline $45-49$ & $8.1 \pm 1.6$ & $5.6 \pm 0.8$ & $5.8 \pm 0.7$ & $8.1 \pm 1.8$ & $7.8 \pm 1.5$ & $10.0 \pm 1.8$ & $7.2 \pm 1.5$ & 4.76 & 0.2 \\
\hline $50-54$ & $11.5 \pm 1.8$ & $8.1 \pm 1.2$ & $7.0 \pm 1.0$ & $9.9 \pm 2.2$ & $12.4 \pm 2.1$ & $11.9 \pm 2.6$ & $12.4 \pm 2.4$ & 10.31 & 0.1 \\
\hline $55-59$ & $10.3 \pm 1.8$ & $9.6 \pm 1.2$ & $9.7 \pm 1.1$ & $17.3 \pm 2.3$ & $17.3 \pm 2.3$ & $16.3 \pm 2.8$ & $10.2 \pm 2.1$ & 6.05 & 0.2 \\
\hline $60-64$ & $16.3 \pm 2.4$ & $13.2 \pm 1.6$ & $11.7 \pm 1.4$ & $14.4 \pm 2.8$ & $14.9 \pm 2.6$ & $22.4 \pm 3.1$ & $13.5 \pm 2.8$ & 5.50 & 0.3 \\
\hline $65-69$ & $23.0 \pm 2.2$ & $12.6 \pm 1.4$ & $18.5 \pm 1.2$ & $19.4 \pm 2.8$ & $27.3 \pm 3.1$ & $21.7 \pm 3.0$ & $22.3 \pm 3.7$ & 9.90 & 0.2 \\
\hline \multicolumn{10}{|l|}{ Gender } \\
\hline Women & $11.4 \pm 1.0$ & $8.2 \pm 0.6$ & $8.1 \pm 0.5$ & $11.9 \pm 1.2$ & $12.8 \pm 1.1$ & $12.2 \pm 1.2$ & $10.3 \pm 1.1$ & 4.95 & 0.3 \\
\hline Men & $13.1 \pm 1.8$ & $9.8 \pm 1.1$ & $10.6 \pm 1.0$ & $13.5 \pm 2.2$ & $15.9 \pm 2.1$ & $20.3 \pm 2.7$ & $15.1 \pm 2.4$ & 4.64 & 0.4 \\
\hline \multicolumn{10}{|l|}{ Educational level } \\
\hline $\begin{array}{l}\text { Illiteracy to secondary school } \\
\text { (grade } 9 \text { and below) }\end{array}$ & $12.4 \pm 1.2$ & $8.8 \pm 0.7$ & $10.2 \pm 0.6$ & $12.2 \pm 1.5$ & $13.7 \pm 1.2$ & $15.0 \pm 1.5$ & $11.5 \pm 1.4$ & 5.78 & 0.2 \\
\hline High school (grade 10-12) & $9.8 \pm 1.5$ & $8.2 \pm 1.1$ & $7.0 \pm 0.8$ & $12.0 \pm 1.8$ & $14.1 \pm 1.9$ & $14.8 \pm 2.3$ & $12.4 \pm 1.9$ & 10.78 & 0.1 \\
\hline College or more & $9.1 \pm 2.3$ & $7.3 \pm 1.4$ & $6.3 \pm 1.1$ & $11.6 \pm 2.4$ & $11.5 \pm 2.7$ & $8.6 \pm 2.6$ & $8.5 \pm 2.8$ & 5.37 & 0.4 \\
\hline \multicolumn{10}{|l|}{ Region } \\
\hline Rural & NA & $7.4 \pm 0.8$ & $9.0 \pm 0.9$ & NA & NA & $14.8 \pm 1.7$ & $13.4 \pm 1.5$ & NA & NA \\
\hline Urban & $11.8 \pm 0.9$ & $9.2 \pm 0.7$ & $8.7 \pm 0.5$ & $12.1 \pm 1.1$ & $13.5 \pm 1.0$ & $14.7 \pm 1.7$ & $10.3 \pm 1.0$ & 4.87 & 0.3 \\
\hline
\end{tabular}

Values are presented as $\% \pm$ standard error.

APC, annual percent change; NA, not applicable.

'Data are direct age adjustment of the data was done for the Vietnamese population aged $\geq 45$ years in the year 2009. 
Ton TT et al. : Prevalence trends of prediabetes/diabetes in Vietnam

Table 3. Age-standardized prevalence of prediabetes among study participants from 2011 to $2017(n=12,725)^{1}$

\begin{tabular}{|c|c|c|c|c|c|c|c|c|c|}
\hline Characteristics & 2011 & 2012 & 2013 & 2014 & 2015 & 2016 & 2017 & APC (\%) & $p_{\text {trend }}$ \\
\hline No. of respondents (n) & 1,530 & 2,998 & 3,982 & 994 & 1,251 & 981 & 989 & - & - \\
\hline $\begin{array}{l}\text { No. of participants with } \\
\text { prediabetes }(n)\end{array}$ & 469 & 632 & 1,248 & 540 & 659 & 489 & 522 & - & - \\
\hline \multicolumn{10}{|l|}{ Prevalence overall } \\
\hline Crude & $30.7 \pm 1.2$ & $21.1 \pm 0.7$ & $31.3 \pm 0.7$ & $54.3 \pm 1.6$ & $52.7 \pm 1.4$ & $49.8 \pm 1.6$ & $52.8 \pm 1.6$ & 15.24 & $<0.001$ \\
\hline Adjusted & $29.4 \pm 1.3$ & $20.2 \pm 0.8$ & $30.6 \pm 0.8$ & $53.4 \pm 1.7$ & $53.3 \pm 1.5$ & $48.7 \pm 1.7$ & $52.9 \pm 1.6$ & 16.17 & $<0.001$ \\
\hline \multicolumn{10}{|l|}{ Age (yr) } \\
\hline $45-49$ & $25.4 \pm 2.6$ & $19.4 \pm 1.4$ & $29.5 \pm 1.4$ & $49.2 \pm 3.3$ & $52.2 \pm 2.8$ & $46.1 \pm 3.0$ & $47.5 \pm 2.9$ & 14.54 & $<0.001$ \\
\hline $50-54$ & $29.1 \pm 2.5$ & $18.1 \pm 1.6$ & $30.2 \pm 1.8$ & $54.4 \pm 3.7$ & $56.6 \pm 3.1$ & $46.9 \pm 4.0$ & $56.5 \pm 3.6$ & 21.24 & $<0.001$ \\
\hline $55-59$ & $32.6 \pm 2.7$ & $19.4 \pm 1.6$ & $29.3 \pm 1.7$ & $56.8 \pm 3.3$ & $52.7 \pm 3.0$ & $50.6 \pm 3.8$ & $57.8 \pm 3.5$ & 16.64 & $<0.001$ \\
\hline $60-64$ & $33.7 \pm 3.0$ & $24.3 \pm 2.0$ & $33.0 \pm 2.0$ & $53.8 \pm 4.0$ & $56.2 \pm 3.6$ & $53.6 \pm 3.7$ & $53.5 \pm 4.0$ & 17.29 & $<0.001$ \\
\hline $65-69$ & $32.4 \pm 2.4$ & $25.9 \pm 1.9$ & $34.7 \pm 1.5$ & $58.2 \pm 3.5$ & $45.5 \pm 3.5$ & $53.4 \pm 3.6$ & $50.8 \pm 4.4$ & 16.28 & $<0.001$ \\
\hline \multicolumn{10}{|l|}{ Gender } \\
\hline Women & $31.1 \pm 1.5$ & $22.3 \pm 0.9$ & $33.3 \pm 1.0$ & $55.6 \pm 2.0$ & $54.2 \pm 1.7$ & $50.3 \pm 2.0$ & $52.8 \pm 1.9$ & 14.09 & $<0.001$ \\
\hline Men & $24.8 \pm 2.3$ & $14.5 \pm 1.3$ & $23.9 \pm 1.4$ & $48.1 \pm 3.3$ & $51.0 \pm 3.0$ & $44.5 \pm 3.4$ & $53.4 \pm 3.3$ & 12.75 & $<0.001$ \\
\hline \multicolumn{10}{|l|}{ Educational level } \\
\hline $\begin{array}{l}\text { Illiteracy to secondary } \\
\text { school (grade } 9 \text { and below) }\end{array}$ & $31.4 \pm 1.8$ & $20.6 \pm 1.0$ & $31.3 \pm 1.1$ & $53.8 \pm 2.5$ & $55.5 \pm 1.9$ & $49.8 \pm 2.2$ & $55.3 \pm 2.2$ & 16.68 & $<0.001$ \\
\hline High school (grade 10-12) & $27.7 \pm 2.2$ & $19.3 \pm 1.5$ & $30.4 \pm 1.5$ & $52.6 \pm 2.9$ & $49.8 \pm 2.8$ & $46.5 \pm 3.3$ & $48.7 \pm 3.0$ & 14.65 & $<0.001$ \\
\hline College or more & $26.8 \pm 3.2$ & $21.5 \pm 2.2$ & $28.0 \pm 2.1$ & $56.7 \pm 3.8$ & $51.0 \pm 4.3$ & $49.4 \pm 4.8$ & $50.9 \pm 4.7$ & 16.57 & 0.1 \\
\hline \multicolumn{10}{|l|}{ Region } \\
\hline Rural & NA & $18.2 \pm 1.2$ & $34.0 \pm 1.6$ & NA & NA & $47.8 \pm 2.4$ & $57.6 \pm 2.3$ & NA & NA \\
\hline Urban & $29.3 \pm 1.3$ & $21.4 \pm 1.0$ & $29.2 \pm 0.9$ & $53.3 \pm 1.7$ & $53.3 \pm 1.5$ & $49.7 \pm 2.5$ & $48.4 \pm 2.3$ & 16.37 & $<0.001$ \\
\hline
\end{tabular}

Values are presented as $\% \pm$ standard error.

APC, annual percent change; NA. not applicable.

'Direct age adjustment of the data was done for the Vietnamese population aged $\geq 45$ years in the year 2009 .

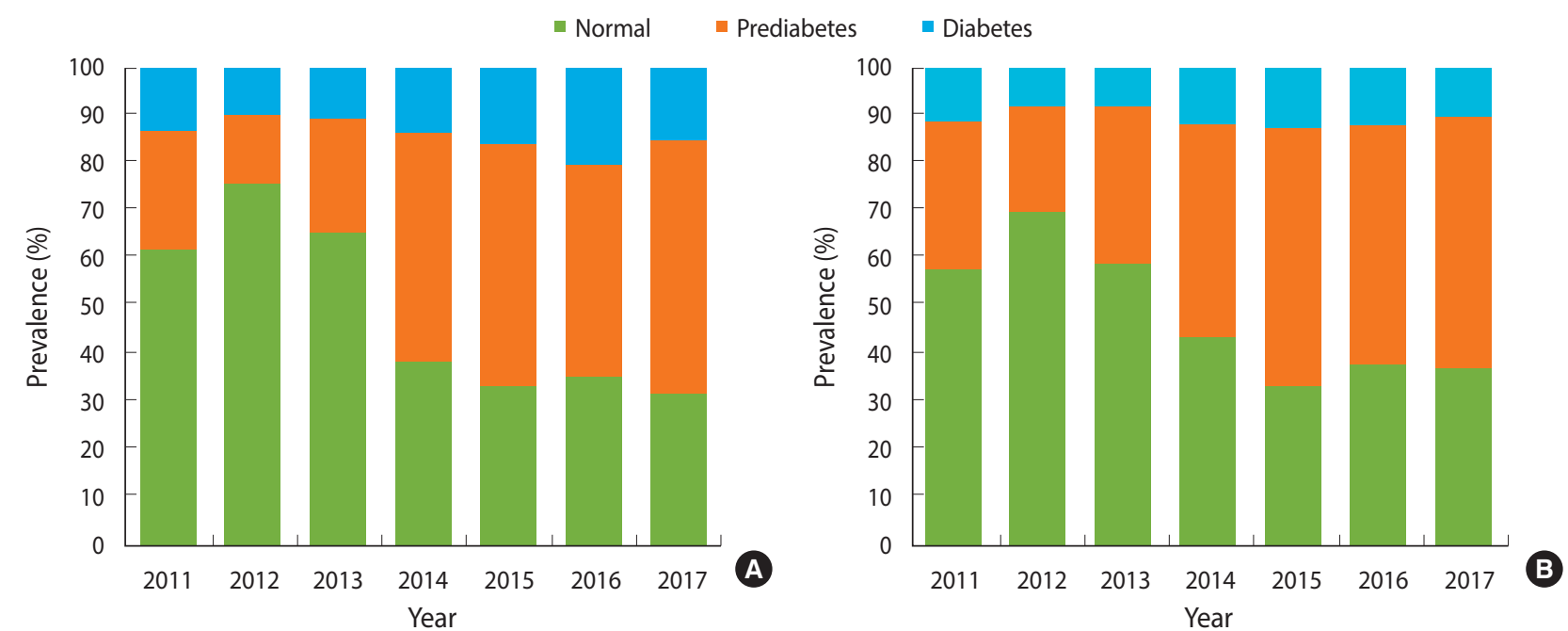

Figure 1. Prevalence of diabetes and prediabetes in Da Nang from 2011 to 2017, by gender (A: men, B: women).

lence of prediabetes was $29.4 \%$ in 2011 and $52.9 \%$ in 2017 ( $\mathrm{p}_{\text {trend }}<$ 0.001), with an APC of $16.17 \%$. Increasing trends of prediabetes were observed in all age groups, for both genders, in all urban areas, and for educational levels lower than college.
Trends in the prevalence of diabetes and prediabetes using only FPG levels are shown in Supplementary Materials 1 and 2. The age-adjusted prevalence (using FPG) was $10.4 \%$ and $53.2 \%$ for diabetes and prediabetes, respectively, in 2017. A significant increase 


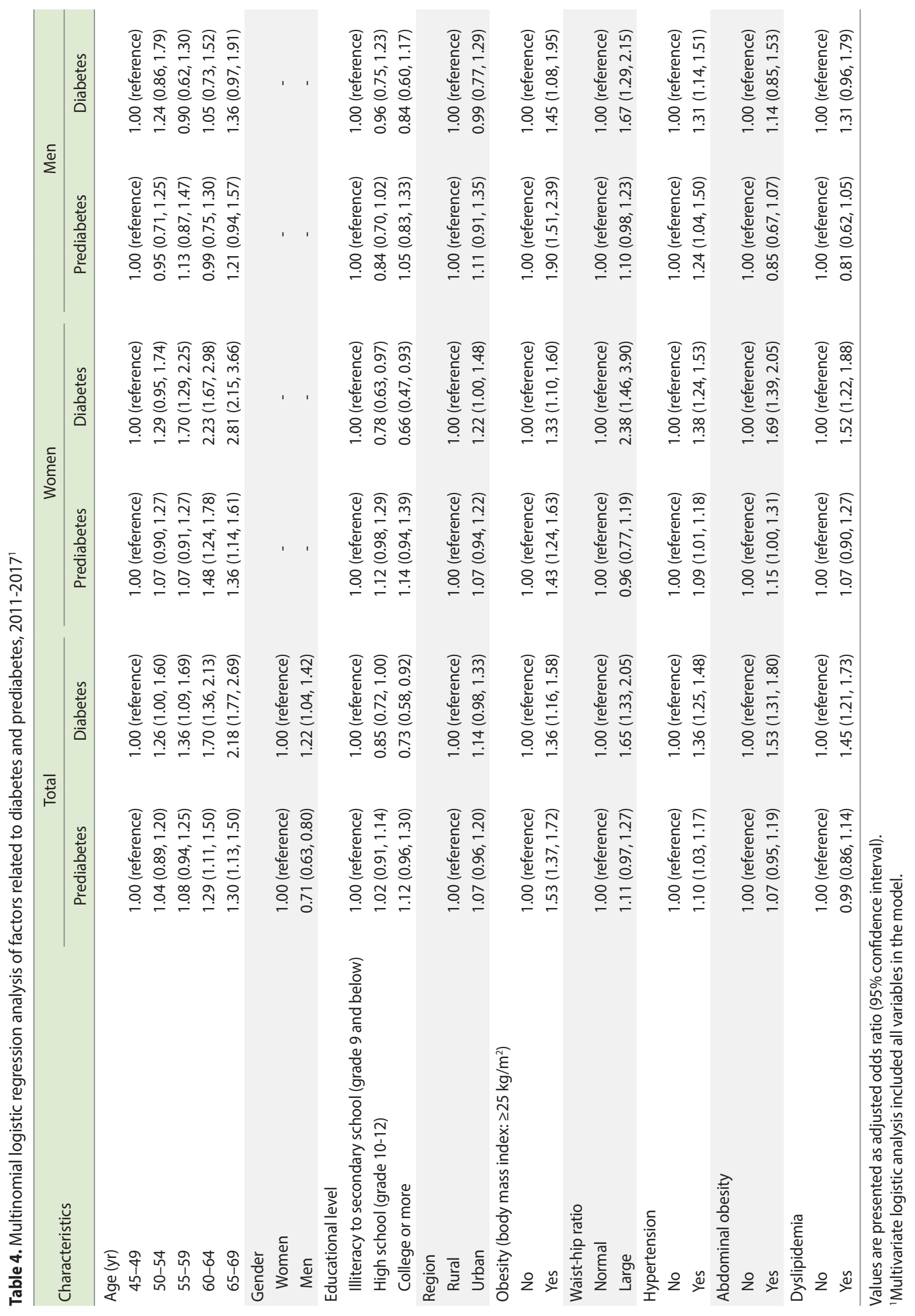


was found in the prevalence of diabetes using the FPG definition among those aged 50-54 years and among those with an educational level of grade 9 and below. However, the prevalence of prediabetes based on FPG alone remained similar from 2011 to 2017 in men and in those with an educational attainment of college or higher.

Figure 1 shows that the disparity in the prevalence of diabetes and prediabetes by gender, which increased dramatically since 2012, when the lowest prevalence was recorded in both groups. The prevalence of prediabetes was lower in men than in women during the period 2011-2016, and then was similar in 2017 (52.8\% in women and $53.4 \%$ in men). In contrast, the prevalence of diabetes remained higher in men than in women throughout the period of 2011 to 2017 (in 2017, 15.1\% in men and 10.3\% in women).

Table 4 shows the associations of risk factors with prediabetes and diabetes. Overall, the risk of prediabetes was higher in people with obesity (BMI $\geq 25 \mathrm{~kg} / \mathrm{m}^{2}$; adjusted odds ratio [aOR], 1.53; 95\% CI, 1.37 to 1.72 ) and hypertension (aOR, 1.10; 95\% CI, 1.03 to 1.17 ). In contrast, men had a lower risk of prediabetes than women ( $\mathrm{aOR}, 0.71 ; 95 \% \mathrm{CI}, 0.63$ to 0.80 ). The risk of diabetes was elevated in men (aOR, 1.22; 95\% CI, 1.04 to 1.42 ) and individuals with obesity (aOR, 1.36; 95\% CI, 1.16 to 1.58 ), hypertension (aOR, 1.36; 95\%CI, 1.25 to 1.48), abdominal obesity (aOR, 1.53; 95\% CI, 1.31 to 1.80 ), a high WHR (aOR, 1.65; 95\% CI, 1.33 to 2.05), and dyslipidemia (aOR, 1.45; 95\% CI, 1.21 to 1.73 ). Older age increased the risk of prediabetes and diabetes, with statistical significance in women, but no statistical significance in men. Supplementary Material 3 shows a binary logistic regression analysis of factors related to prediabetes and diabetes. The major risk factors were found to be similar to those found in the multinomial logistic regression model.

\section{DISCUSSION}

This paper presents information on trends in the age-standardized prevalence of prediabetes and diabetes in the Vietnamese population aged 45 years and older during a 7 -year period using the latest provincial screening database. Our findings revealed that about $11.4 \%$ of people had diabetes, and 1 out of 2 had prediabetes in 2017. The results of this study also indicated that the prevalence of prediabetes significantly increased in the analyzed population from 2011 to 2017, with an APC of $16.17 \%$, whereas no significant trend in diabetes prevalence was observed in this period. Our study identified positive associations of gender, age over 60 years, obesity, a high WHR, hypertension, dyslipidemia and abdominal obesity with diabetes prevalence. Obesity, hypertension, also showed positive relationships with prediabetes.

The prevalence found in this study are higher than other recent regional estimates in the northern and southern areas of Vietnam [8,16-18] and even the national prevalence in a previous systematic review [19]. For example, a study analyzing diabetes prevalence during 2011-2013 in mountainous provinces in northern Vietnam found that $5.6 \%$ of adults aged $30-69$ years old were liv- ing with diabetes [8]. Additionally, 3.7\% of those aged over 40 years were found to have diabetes in a study of inhabitants of rural areas in the southwest of the Red River Delta in 2011 [20]. Our findings are consistent with those of other previous studies that also showed a higher prevalence of diabetes in Vietnam than in other Asian countries [8]. Discrepancies among studies may be at least partially due to differences in research sites, as most previous studies were conducted in rural areas. Differences in the study population are also a relevant factor, as our study only included adults aged over 45 years, which is a high-risk group. Furthermore, over the 7-year period of the study, the proportion of the 65-69 age group increased significantly, which partially contributed to the increase in the prevalence of diabetes and prediabetes. Nonetheless, our findings are similar to those of a study in Chi Linh, a northern city in which $15.9 \%$ of those aged $50-69$ years were living with diabetes [10], a study in the south central coast of Vietnam that reported prevalence rates of $8.1 \%$ for diabetes and $50.1 \%$ for prediabetes [9], and a study conducted in the South Central Coast province, namely Khanh Hoa that reported a 20\% prevalence of diabetes among those aged over 40 years [21]. Our results also align with those of other Asian middle-aged populations, for example, Thailand ( $>13.5 \%$ with diabetes in 2014) or China ( $>11.3 \%$ with diabetes in 2016) [22], Japanese adults aged over 40 years (men: 19.4\%; women: 9.1\%) [23], and adults in the United States [24]. Nevertheless, the estimate was lower than that of a study conducted during 2006-2014 in Hong Kong, China, which found that roughly $40 \%$ of the age group $40-79$ years had diabetes [25].

Interestingly, the prevalence of diabetes did not change significantly over the 7-year period of the study ( $\mathrm{p}_{\text {trend }}>0.05$ ), and remained stable from $11.8 \%$ in 2011 to $11.4 \%$ in 2017 . This pattern is unlike the significant increasing trend found in Thailand from 2004 to 2014 [26], in Japan from 1988 to 2012 [23], and in China from 2006 to 2014 [25]. These differences may be partly due to variation in healthcare systems and services across countries. Another explanation is that our study analyzed the most recent data and covered a longer duration of follow-up than other prior studies. Our findings are contrary to those of an earlier meta-analysis showing an increasing trend in the national diabetes prevalence in Vietnam, from $2.7 \%$ in 2002 to $5.4 \%$ in 2012 [19]. This is partly a result of the diabetes prevention and management program provided in Da Nang since 2010 by the Center for Disease Control and Prevention with financial support from the Da Nang Ministry of Health. The routine annual implementation of NCDs screening programs has facilitated the early detection of prediabetes and diabetes among the population of Da Nang. Indeed, the plateauing trend of diabetes prevalence aligns with the stable trends observed in obesity and hypertension in the study population, which also agrees with a study in Thailand [26]. Our study revealed that the prevalence of diabetes based on FPG levels was lower than that based on a combination of FPG levels with OGTT results. In contrast, prediabetes appeared at a higher level. Because OGTT results were not included in the estimations, some indi- 
viduals with high 2-hour postload OGTT levels may have been missed among those with prediabetes, and fewer people were diagnosed with diabetes. The finding of a significant increase in diabetes prevalence (defined using FPG levels) among adults aged 50-54 years and those with a low educational level should be highlighted.

Despite the effectiveness of diabetes control, it is remarkable that the age-standardized prevalence of prediabetes among the inhabitants of Da Nang still showed a significant increasing trend in all age groups, both genders, all educational levels, and all urban areas, and remained at a consistently high level. This trend is similar to that reported by other studies in Japan [23] and Hong Kong [25], and it is also consistent with the worldwide trend for prediabetes to become more common over the past few decades $[27,28]$. Urbanization in Da Nang may have contributed to an increasing threat posed by multiple lifestyle risk factors, including a sedentary lifestyle, less physical activity, eating fast food, smoking, and alcohol drinking in the most recent decade. This pattern was predominant in the 50-54 age group, which is exposed to many risk factors of prediabetes, increasing the risk that they will suffer from diabetes in their next stage of life. This finding also suggests that health education encouraging individuals to change their risk behaviors should be enhanced as a way to reduce the prediabetes rate among Da Nang residents.

The major causes of diabetes and prediabetes listed in our study were obesity (BMI $\geq 25 \mathrm{~kg} / \mathrm{m}^{2}$ ) and hypertension in both men and women. These risk exposures have also been identified as important contributors in previous studies $[5,17,29]$. The odds ratio of diabetes was higher in those with a higher WHR in both men and women and in women with abdominal obesity and dyslipidemia, which is consistent with an earlier study in Vietnam [8]. Diabetes was found to be less common among those with higher educational levels, as they might have better knowledge about health information and diabetes prevention methods, spurring them to engage in healthier behaviors [26]. Diabetes was more common in men than in women; however, the converse trend was found for prediabetes, in contrast to some previous studies $[8,26]$. This can be explained by the fact that most of our study participants were women, who are more likely than men to have healthier behaviors and to care about their health. We also found a positive association of age with prediabetes and diabetes risk. These results are in line with those of earlier studies in Vietnam, Asia, and worldwide $[24,29,30]$. Our study did not identify a relationship between living areas with high glucose tolerance, as was demonstrated in previous research [19]. This may have been due to the imbalance of urban and rural populations in our study, as most of the participants lived in an urban area.

To our knowledge, this is the most up-to-date study on trends in diabetes and prediabetes prevalence among the Vietnamese population. Data were obtained through a community screening program, which was implemented consistently and comprehensively for the study population. The study was only conducted in the city of Da Nang, limiting its generalizability to the broader population. However, the feasibility of the program is currently challenged by financial constraints; thus, there are currently only a few provinces and cities in Vietnam that are regularly conducting community-based diabetes screening on an annual basis. Therefore, we believe that the results of our study can provide some good practical evidence in terms of the NCDs prevention programs.

Despite the strengths of this study, some limitations should be considered and, ideally, eliminated in further studies. Firstly, there were some limitations in our sample selection process and measurements due to a lack of financial resources. The overall response rate of $62.8 \%$ in our study was lower than the recommended rate [31], particularly in the first years of screening implementation. Additionally, the participation of women and those living in urban areas was disproportionately high in our study, with the proportion of women consistently exceeding $70 \%$ and a roughly even balance of urban and rural inhabitants only being achieved in the last 2 years of the study. These imbalances may have increased the risk of selection bias, as those who were aware of their diabetes risk were more likely to come for screening than others. This factor may have resulted in an overestimation of prediabetes prevalence. Also, due to financial constraints, only approximately half of the participants with higher risks of diabetes received 2-hour OGTT testing. Secondly, the lack of quality control in the laboratory is an important limitation of our study, with possible impacts on study results. Thirdly, we did not collect data on economic characteristics or other health behaviors, such as smoking, alcohol drinking, or diet, all of which are possible confounders. Finally, despite these promising results, our present study derives from cross-sectional observations, so it is not possible to infer causality. Further studies on this issue are therefore recommended.

Overall, this study showed higher diabetes and prediabetes prevalence in the city of Da Nang than in other provinces in Vietnam and in other Asian countries. The prevalence of prediabetes significantly increased over the 7-year study period, but that of diabetes was unchanged. We also estimated several risk factors that might have contributed to the growth in diabetes and prediabetes prevalence over the period. Despite this limitation, these findings have significant implications regarding the need for the government and professional bodies to focus on public health interventions targeting middle-aged Vietnamese adults with the aim of preventing and controlling prediabetes and diabetes nationwide.

\section{SUPPLEMENTARY MATERIALS}

Supplementary materials are available at http://www.e-epih.org/.

\section{CONFLICT OF INTEREST}

The authors have no conflicts of interest to declare for this study. 


\section{FUNDING}

This research was received funding from the "International Cooperation \& Education Program (\#NCCRI - NCCI 52210-52211, 2019-2020)" of the National Cancer Center, South Korea.

\section{ACKNOWLEDGEMENTS}

None.

\section{AUTHOR CONTRIBUTIONS}

Conceptualization: ITD, TTT. Data curation: ITD, TTT, HN. Formal analysis: ITD, ATNT, TTBN, VABH, AQT, HKH. Funding acquisition: ITD, TTT. Methodology: ITD, ATNT, TTT, HN, TTBN, VABH, AQT, HKH, BTT. Project administration: ITD, TTT, MTN, HN. Visualization: ITD, ATNT, BTT. Writing - original draft: ATNT, BTT, ITD, TTT, HN, TTBN, MTN, VABH, AQT, HKH. Writing - review \& editing: BTT.

\section{ORCID}

That Thanh Ton: https://orcid.org/0000-0002-1344-1193; Anh Thi Ngoc Tran: https://orcid.org/0000-0003-4062-323X; Ich Thanh Do: $h t t p s: / / o r c i d . o r g / 0000-0003-1028-5911$; Hoa Nguyen: https:// orcid.org/0000-0002-7032-5017; Thi Thanh Binh Nguyen: https:// orcid.org/0000-0002-1864-3245; Minh Tu Nguyen: https://orcid. org/0000-0002-5040-7162; Van Anh Bao Ha: https://orcid.org/00000002-0129-9097; Anh Quoc Tran: https://orcid.org/0000-0002-26014019; Huu Khoi Hoang: https://orcid.org/0000-0002-2298-8609; Binh Thang Tran: https://orcid.org/0000-0002-8179-4927

\section{REFERENCES}

1. World Health Organization. Global report on diabetes; 2016 [cited 2020 May 28]. Available from: https://apps.who.int/iris/handle/10665/204871.

2. World Health Organization. Definition and diagnosis of diabetes mellitus and intermediate hyperglycaemia: report of a WHO/ IDF consultation; 2006 [cited 2020 May 28]. Available from: https://www.who.int/diabetes/publications/diagnosis_diabetes2006/ en/.

3. Mainous AG 3rd, Tanner RJ, Baker R. Prediabetes diagnosis and treatment in primary care. J Am Board Fam Med 2016;29:283285.

4. Beagley J, Guariguata L, Weil C, Motala AA. Global estimates of undiagnosed diabetes in adults. Diabetes Res Clin Pract 2014; 103:150-160.

5. NCD Risk Factor Collaboration (NCD-RisC). Worldwide trends in diabetes since 1980: a pooled analysis of 751 population-based studies with 4.4 million participants. Lancet 2016;387:1513-1530.

6. International Diabetes Federation. Western pacific: Vietnam; 2020 [cited 2020 May 28]. Available from: https://www.idf.org/ our-network/regions-members/western-pacific/members/119vietnam.html.

7. Le NT, Dinh Pham L, Quang Vo T. Type 2 diabetes in Vietnam: a cross-sectional, prevalence-based cost-of-illness study. Diabetes Metab Syndr Obes 2017;10:363-374.

8. Pham NM, Eggleston K. Prevalence and determinants of diabetes and prediabetes among Vietnamese adults. Diabetes Res Clin Pract 2016;113:116-124.

9. Nguyen VD, Vien QM, Do TH, Phan CD, Nguyen HC, Nguyen VT, et al. Prevalence of undiagnosed diabetes and pre-diabetes and its associated risk factors in Vietnam. J Glob Health Sci 2019; 1:e7.

10. Lan VT, Hoang LT, Linh NT, Quyen BT. Blood glucose disorders and access to health care services among adults aged 30 to 69 years in Chi Linh, Hai Duong, Vietnam. Asia Pac J Public Health 2017;29(5_suppl):45S-52S.

11. Ministry of Health. Joint annual health review 2016; 2017 [cited 2020 May 28]. Available from: https://www.moh.gov.vn/en_US/ web/ministry-of-health.

12. Marathe PH, Gao HX, Close KL. American Diabetes Association standards of medical care in diabetes 2017. J Diabetes 2017;9: 320-324.

13. Chalmers J, MacMahon S, Mancia G, Whitworth J, Beilin L, Hansson L, et al. 1999 World Health Organization-International Society of Hypertension Guidelines for the management of hypertension. Guidelines sub-committee of the World Health Organization. Clin Exp Hypertens 1999;21:1009-1060.

14. World Health Organization. Obesity: preventing and managing the global epidemic; 2000 [cited 2020 May 28]. Available from: https://www.who.int/nutrition/publications/obesity/WHO_TRS_ 894/en/.

15. World Health Organization. Waist circumference and waist-hip ratio; 2011 [cited 2020 May 28]. Available from: https://www. who.int/nutrition/publications/obesity/WHO_report_waistcircumference_and_waisthip_ratio/en/.

16. Pham NM, Eggleston K. Diabetes prevalence and risk factors among Vietnamese adults: findings from community-based screening programs. Diabetes Care 2015;38:e77-e78.

17. Duc Son LN, Kusama K, Hung NT, Loan TT, Chuyen NV, Kunii $\mathrm{D}$, et al. Prevalence and risk factors for diabetes in Ho Chi Minh City, Vietnam. Diabet Med 2004;21:371-376.

18. Nguyen CT, Pham NM, Nguyen QV, Nguyen VQ, La QN, Lee AH. Menopausal status and type 2 diabetes: a nationwide epidemiological survey in Vietnam. Public Health 2016;138:168-169.

19. Nguyen CT, Pham NM, Lee AH, Binns CW. Prevalence of and risk factors for type 2 diabetes mellitus in Vietnam: a systematic review. Asia Pac J Public Health 2015;27:588-600.

20. Quang Binh T, Tran Phuong P, Thi Nhung B, Dinh Thoang D, Van Thang P, Khanh Long T, et al. Prevalence and correlates of hyperglycemia in a rural population, Vietnam: implications from a cross-sectional study. BMC Public Health 2012;12:939.

21. Miyakawa M, Shimizu T, Van Dat N, Thanh P, Thuy PT, Anh NT, et al. Prevalence, perception and factors associated with diabetes 
mellitus among the adult population in central Vietnam: a population-based, cross-sectional seroepidemiological survey. BMC Public Health 2017;17:298.

22. Cai L, Li X, Cui W, You D, Golden AR. Trends in diabetes and pre-diabetes prevalence and diabetes awareness, treatment and control across socioeconomic gradients in rural southwest China. J Public Health (Oxf) 2018;40:375-380.

23. Mukai N, Hata J, Hirakawa Y, Ohara T, Yoshida D, Nakamura U, et al. Trends in the prevalence of type 2 diabetes and prediabetes in a Japanese community, 1988-2012: the Hisayama Study. Diabetol Int 2018;10:198-205.

24. Centers for Disease Control and Prevention. National diabetes statistics report, 2017: estimates of diabetes and its burden in the United States [cited 2020 Apr 1]. Available from: https://dev.diabetes.org/sites/default/files/2019-06/cdc-statistics-report-2017. pdf.

25. Quan J, Li TK, Pang H, Choi CH, Siu SC, Tang SY, et al. Diabetes incidence and prevalence in Hong Kong, China during 2006-2014. Diabet Med 2017;34:902-908.

26. Aekplakorn W, Chariyalertsak S, Kessomboon P, Assanangkornchai S, Taneepanichskul S, Putwatana P. Prevalence of diabetes and relationship with socioeconomic status in the Thai popula- tion: National Health Examination Survey, 2004-2014. J Diabetes Res 2018;2018:1654530.

27. Danaei G, Finucane MM, Lu Y, Singh GM, Cowan MJ, Paciorek CJ, et al. National, regional, and global trends in fasting plasma glucose and diabetes prevalence since 1980: systematic analysis of health examination surveys and epidemiological studies with 370 country-years and 2.7 million participants. Lancet 2011;378:3140.

28. Introduction: standards of medical care in diabetes-2019. Diabetes Care 2019;42(Suppl 1):S1-S2.

29. Satman I, Omer B, Tutuncu Y, Kalaca S, Gedik S, Dinccag N, et al. Twelve-year trends in the prevalence and risk factors of diabetes and prediabetes in Turkish adults. Eur J Epidemiol 2013;28: 169-180.

30. Yang W, Lu J, Weng J, Jia W, Ji L, Xiao J, et al. Prevalence of diabetes among men and women in China. N Engl J Med 2010;362: 1090-1101.

31. Kasper JD, Shapiro S, Guralnik JM, Bandeen-Roche KJ, Fried LP. Designing a community study of moderately to severely disabled older women: the Women's Health and Aging Study. Ann Epidemiol 1999;9:498-507. 